\title{
Preparation of porous carbon materials derived from hyper- cross-linked asphalt/coal tar and their high desulfurization performance
}

Tuo Di, ${ }^{a}$ Yunxia, Xia, ${ }^{a}$ Baoyou Pei, ${ }^{b}$ Tingting Zhu, ${ }^{a}$ Tiansheng Zhao, ${ }^{c}$ Tiesheng $L i,{ }^{d}$ and Lei Li ${ }^{* a}$

a College of Materials and Fujian Provincial Key Laboratory of Materials Genome, Xiamen University, Xiamen 361005, P. R. China. E-mail: lilei@xmu.edu.cn; Fax:

+86-592-2183937; Tel: +86-592-2186296

b College of Chemical Engineering, Huaqiao University, Xiamen, 361021, P.R.

China.

c State Key Laboratory of High-efficiency Utilization of Coal and Green Chemical Engineering, Ningxia University, Yinchuan, 750021, P.R. China.

d College of Chemistry and Molecular Engineering, Zhengzhou University, Zhengzhou, 450001, P.R. China.

Number of pages: 13

Number of figures: 16

Number of tables: 5

\section{Table of Contents}

\section{Supporting Figures}

Figure S1. UV-vis spectra of DBT in model oil before and after adsorption. The peak at $325 \mathrm{~nm}$ can be used to determine the concentration of DBT in model oil.

Figure S2. FT-IR spectra of AS-1 and HAS-1.

Figure S3. FT-IR spectra of AS-2 and HAS-2.

Figure S4. FT-IR spectra of CT-1 and HCT-1.

Figure S5. FT-IR spectra of CT-2 and HCT-2.

Figure S6. FT-IR spectra of CT-3 and HCT-3.

Figure S7. Solid state ${ }^{13} \mathrm{C} \mathrm{CP} / \mathrm{MAS}$ NMR spectra of (a) AS-1 and (b) AS-2. Asterisks denote the spinning sidebands.

Figure S8. XPS spectra of CHCPs.

Figure S9. C 1s XPS spectra of (a) CHAS-2, (b) CHCT-1, (c) CHCT-2 and (d) CHCT-3.

Figure S10. O 1s XPS spectra of (a) CHAS-2, (b) CHCT-1, (c) CHCT-2 and (d) CHCT-3. 
Figure S11. Pore size distribution curves of (a) hyper-cross-linked asphalt/coal and (b) CHCPs (calculated using NLDFT method).

Figure S12. Adsorption curves of CHAS-1, CHAS-2, CHCT-1, CHCT-2 and CHCT-3 in 5 min (Their adsorption capacities are 43.1, 42.7, 41.6, 43.8 and $40.7 \mathrm{mg} \mathrm{S} \mathrm{g}^{-1}$, respectively).

Figure S13. Adsorption curves (The initial concentration of DBT in model oil is $\mathrm{C}_{0}=800 \mathrm{mg} \mathrm{S} \mathrm{L}^{-1}$; the volume of model oil is $3.5 \mathrm{~mL}$; and the mass of adsorbent is $20 \mathrm{mg}$.).

Figure S14. Adsorption curves (The initial concentration of DBT in model oil is $\mathrm{C}_{0}=500 \mathrm{mg} \mathrm{S} \mathrm{L}^{-1}$; the volume of model oil is $10 \mathrm{~mL}$; and the mass of adsorbent is $10 \mathrm{mg}$.).

Figure S15. Adsorption curves (The initial concentration of DBT in model oil is $\mathrm{C}_{0}=50 \mathrm{mg} \mathrm{S} \mathrm{L}^{-1}$; the volume of model oil is $20 \mathrm{~mL}$; and the mass of adsorbent is $5 \mathrm{mg}$.).

Figure S16. Adsorption curves (The initial concentration of DBT in model oil is $\mathrm{C}_{0}=10 \mathrm{mg} \mathrm{S} \mathrm{L}^{-1}$; the volume of model oil is $3.5 \mathrm{~mL}$; and the mass of adsorbent is $20 \mathrm{mg}$.).

\section{Supporting Tables.}

Table S1. The experimental conditions, parameters and yields of resultant carbonaceous materials

Table S2. Chemical compositions of CHCPs samples by XPS analysis

Table S3. Adsorption capacities of applied CHCPs

Table S4. DBT adsorption isotherm parameters for Langmuir and Freundlich equations

Table S5. Adsorption capacities of reported metal-free activated carbons and CHAS-1 


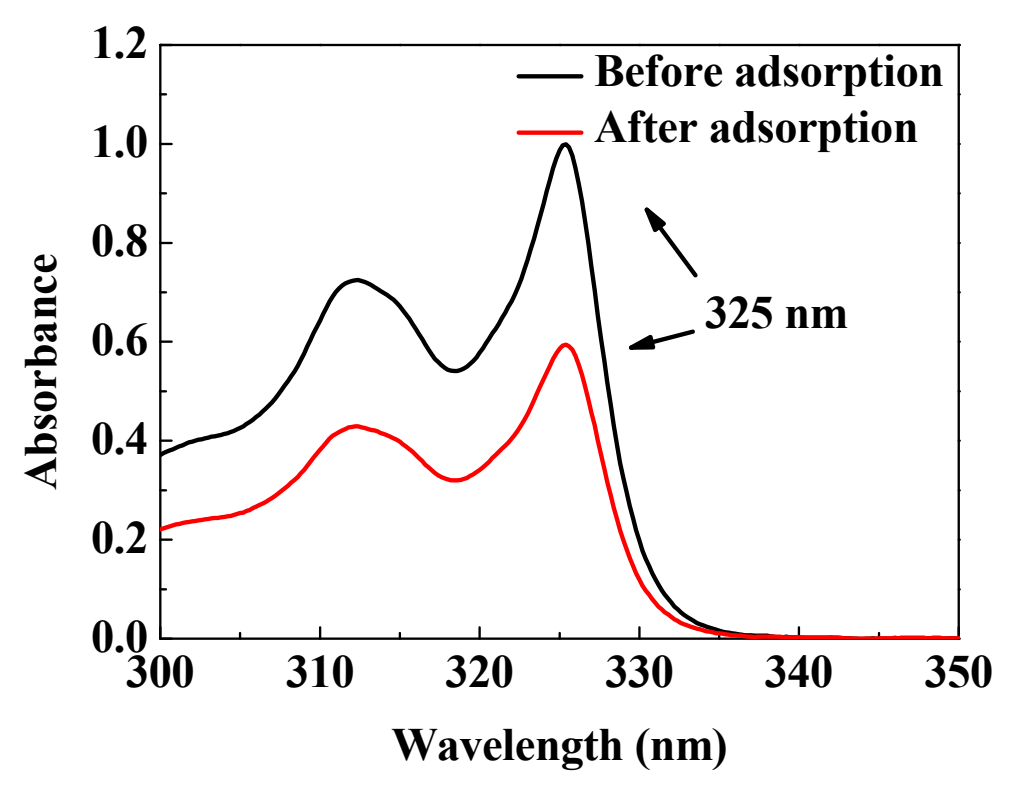

Figure S1. UV-vis spectra of DBT in model oil before and after adsorption. The peak at $325 \mathrm{~nm}$ can be used to determine the concentration of DBT in model oil.

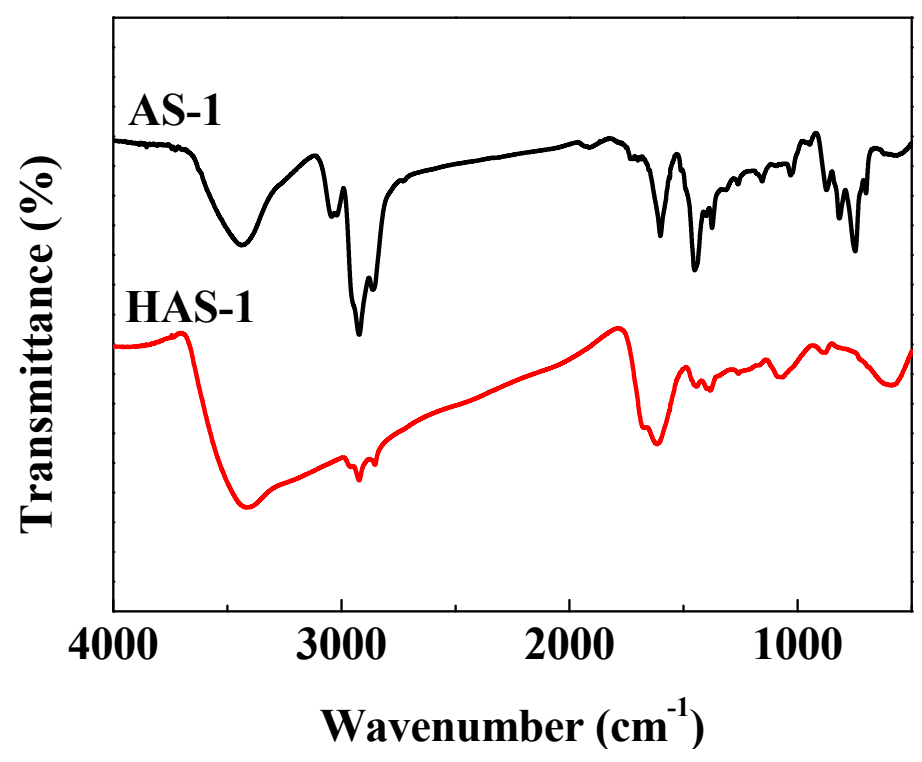

Figure S2. FT-IR spectra of AS-1 and HAS-1. 


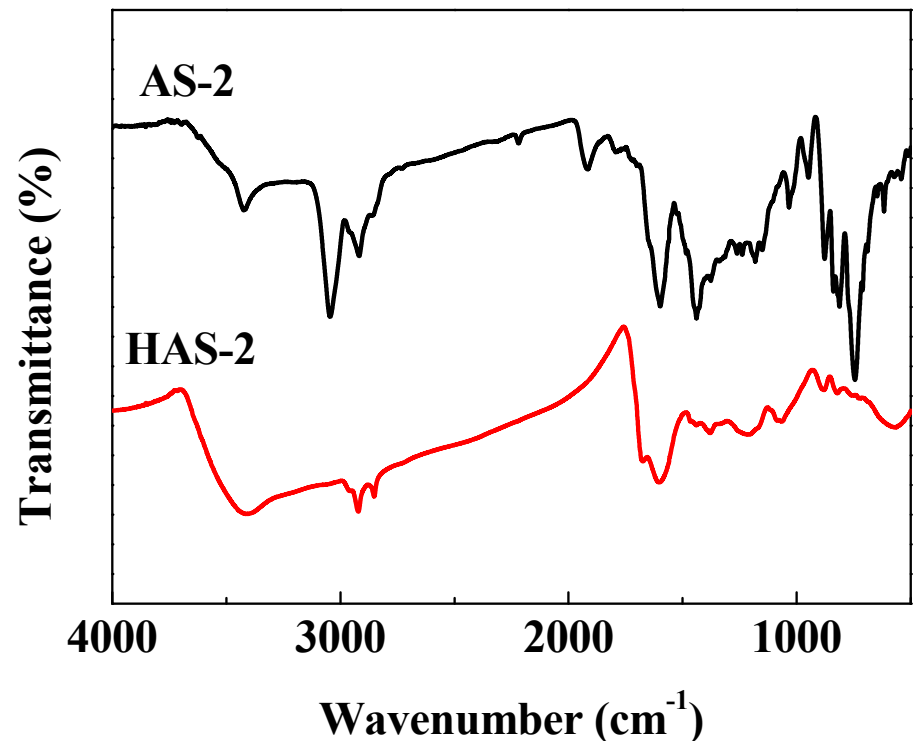

Figure S3. FT-IR spectra of AS-2 and HAS-2.

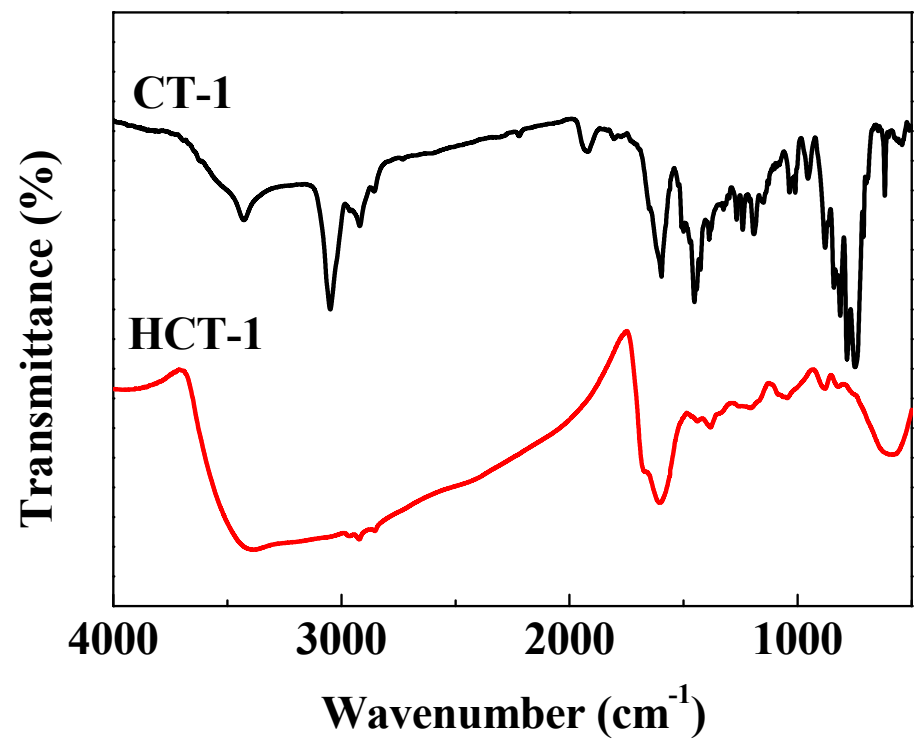

Figure S4. FT-IR spectra of CT-1 and HCT-1. 


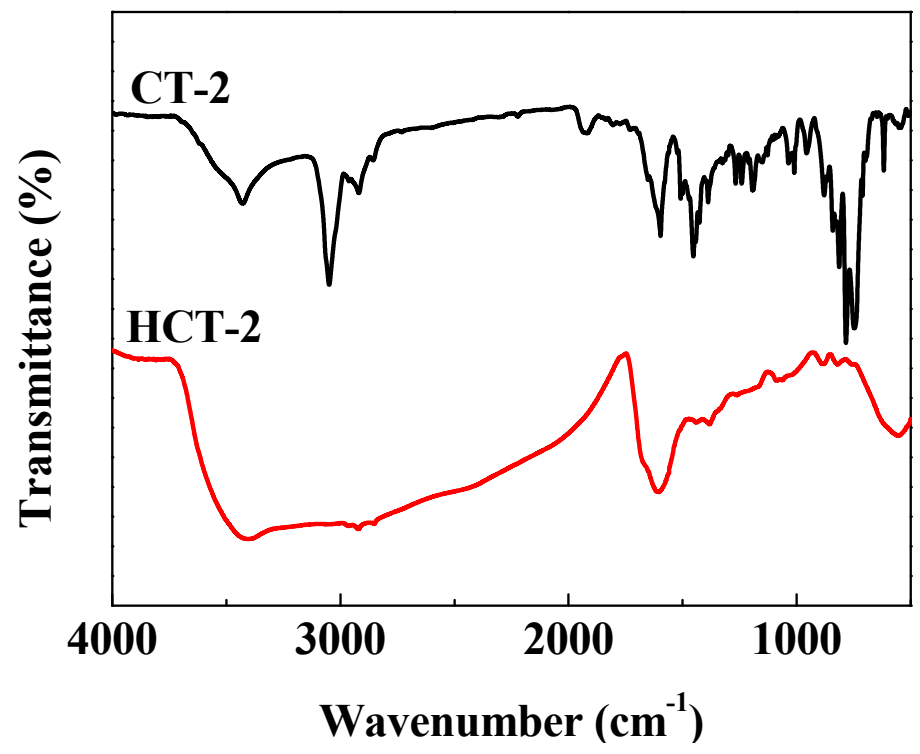

Figure S5. FT-IR spectra of CT-2 and HCT-2.

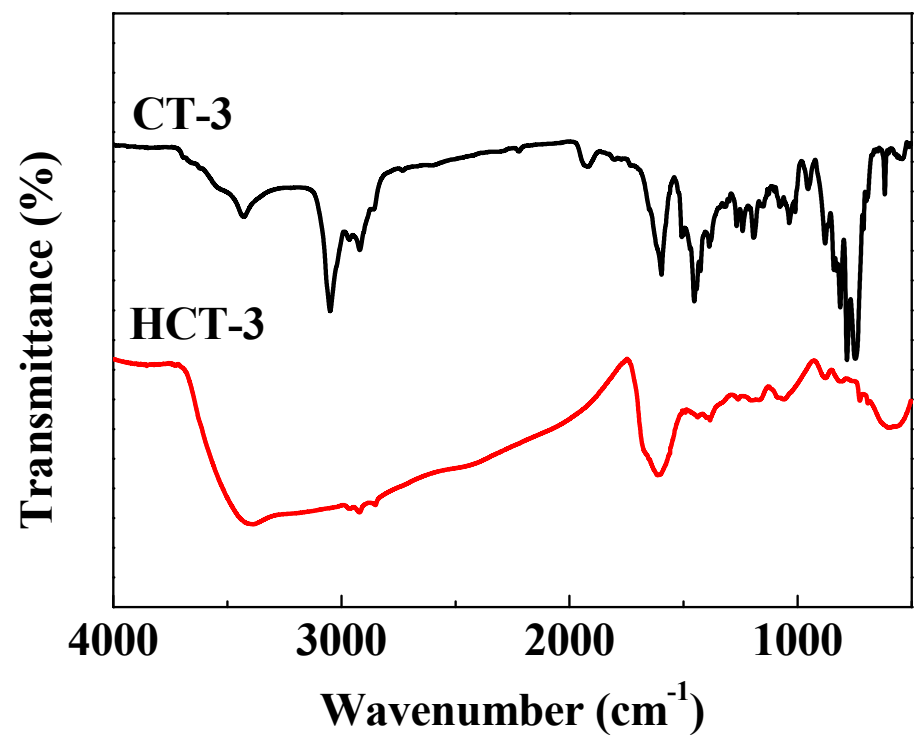

Figure S6. FT-IR spectra of CT-3 and HCT-3. 

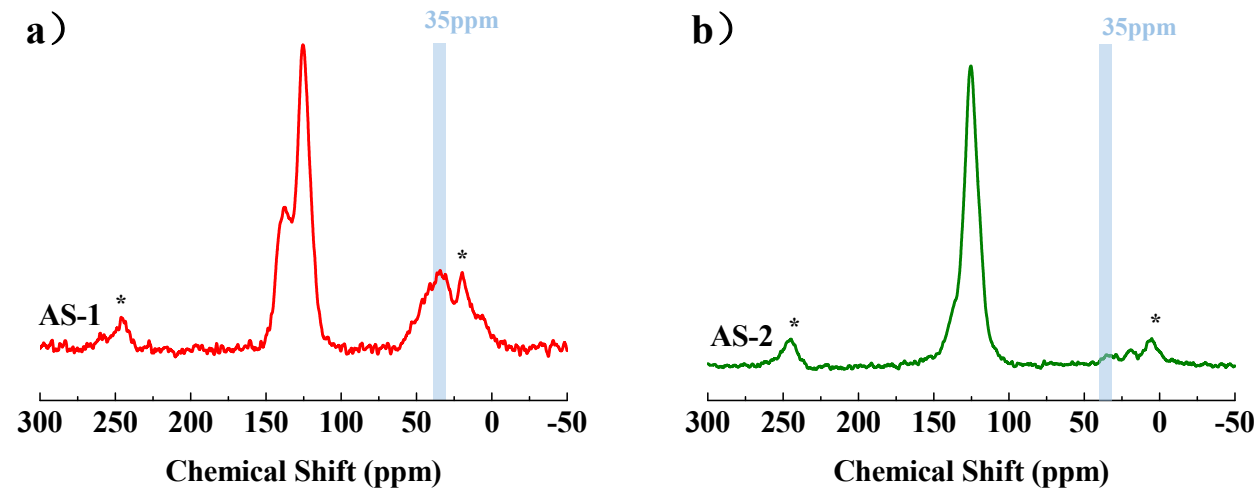

Figure S7. Solid state ${ }^{13} \mathrm{C}$ CP/MAS NMR spectra of (a) AS-1 and (b) AS-2. Asterisks denote the spinning sidebands.

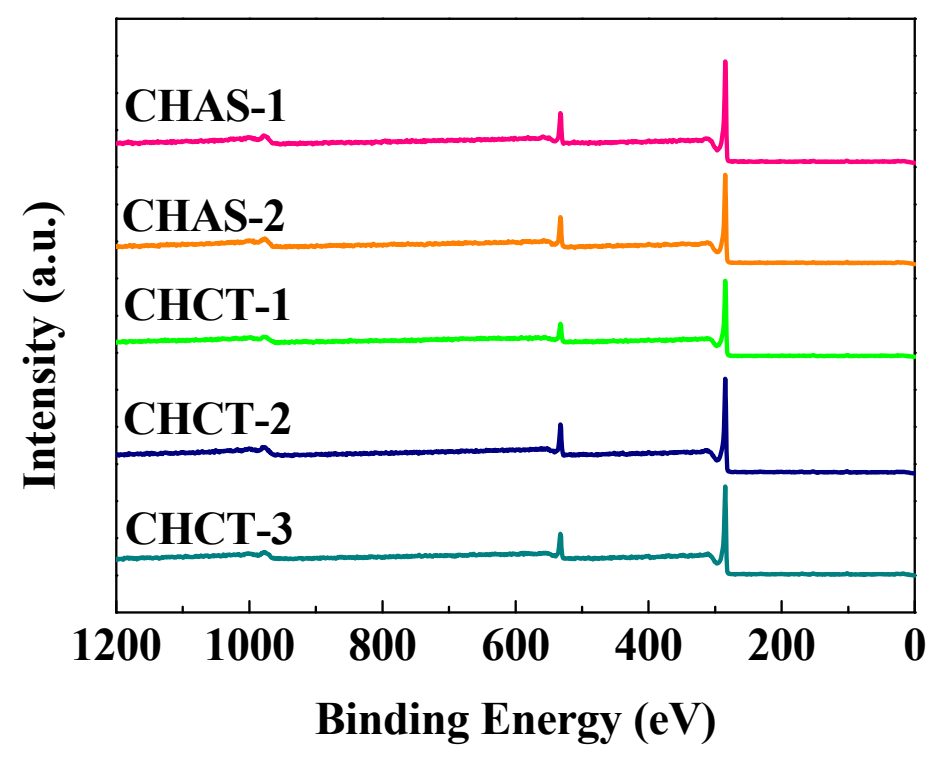

Figure S8. XPS spectra of CHCPs. 

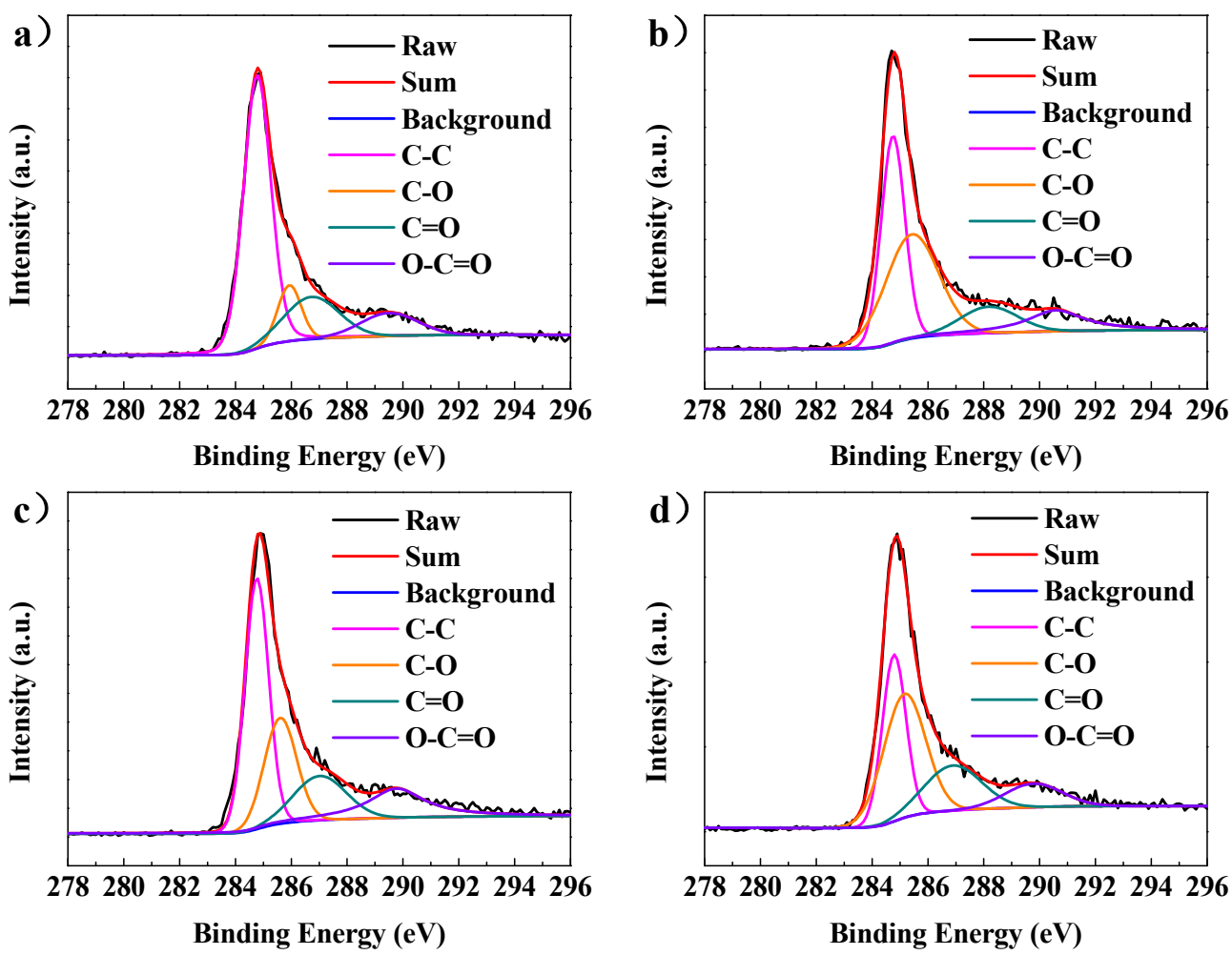

Figure S9. C 1s XPS spectra of (a) CHAS-2, (b) CHCT-1, (c) CHCT-2 and (d) CHCT-3. 

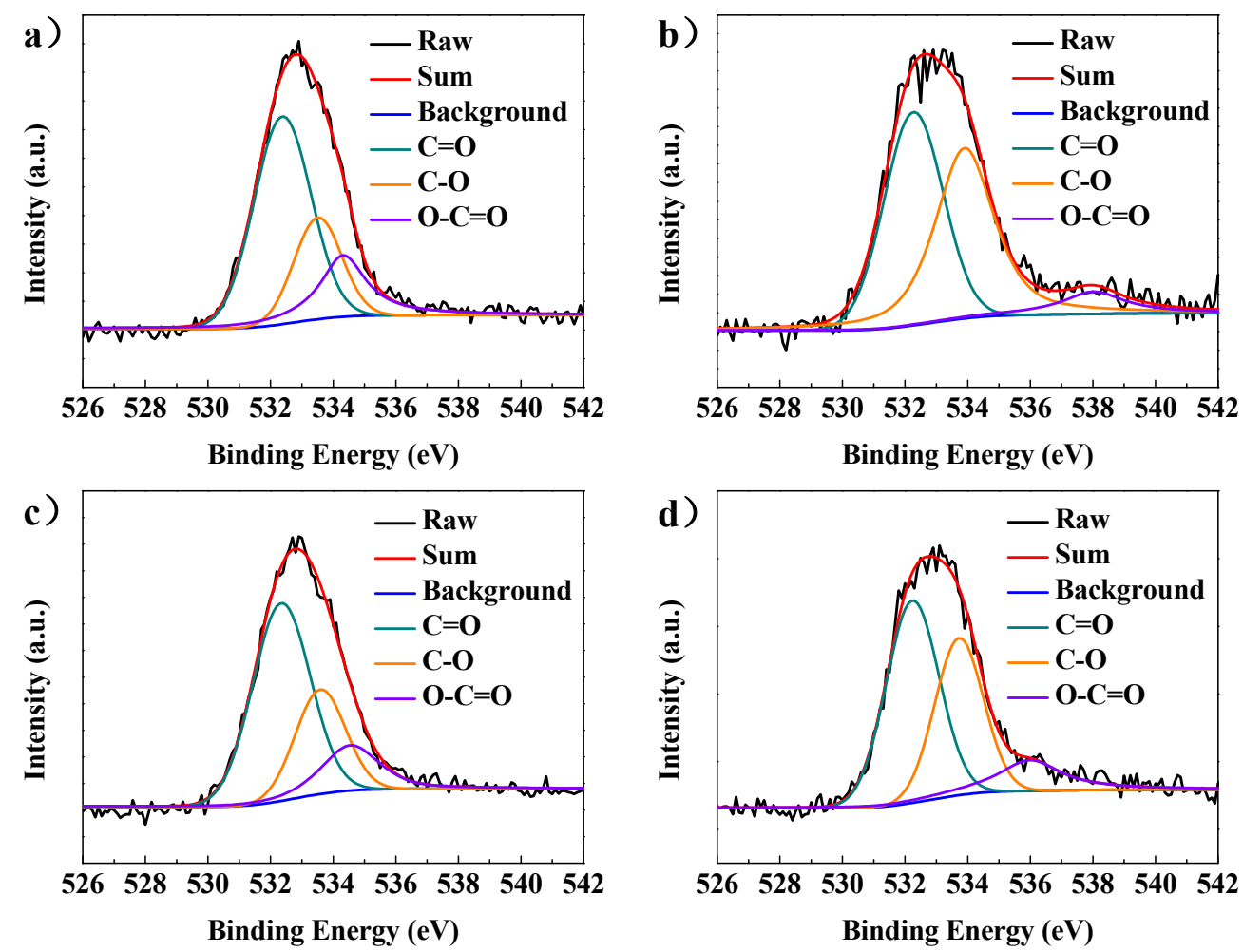

Figure S10. O 1s XPS spectra of (a) CHAS-2, (b) CHCT-1, (c) CHCT-2 and (d) CHCT-3.
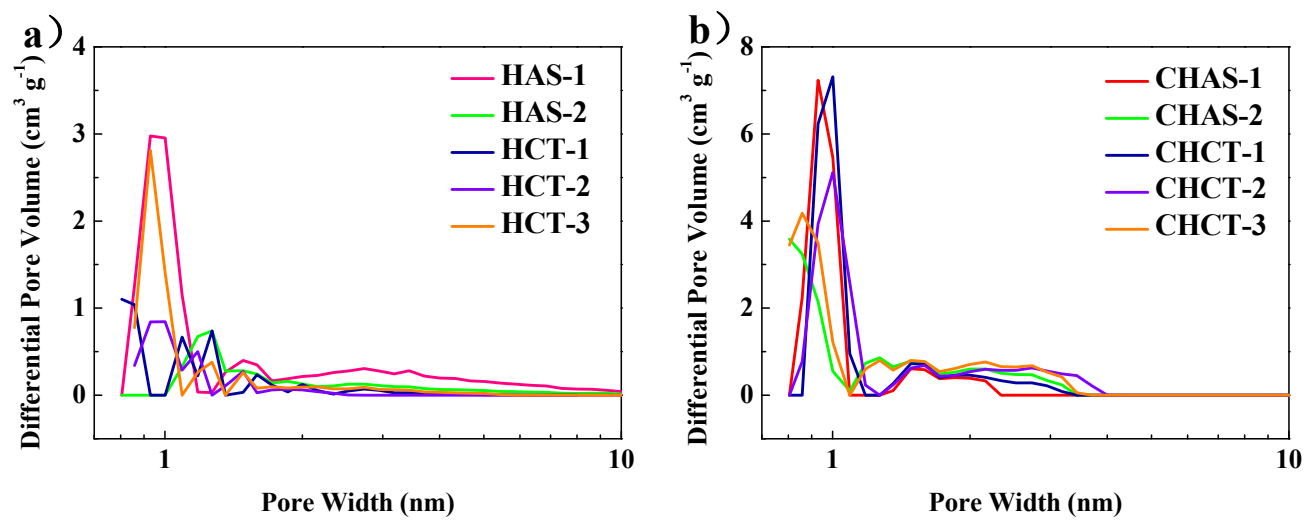

Figure S11. Pore size distribution curves of (a) hyper-cross-linked asphalt/coal and (b) CHCPs (calculated using NLDFT method). 


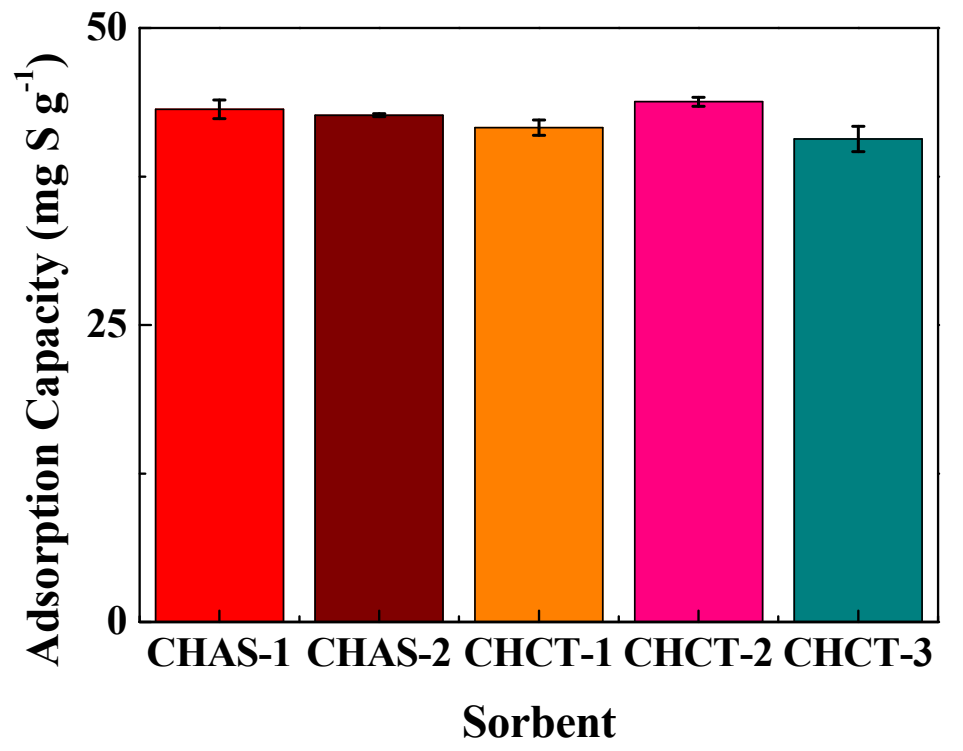

Figure S12. Adsorption curves of CHAS-1, CHAS-2, CHCT-1, CHCT-2 and CHCT-3 in $5 \mathrm{~min}$ (Their adsorption capacities are 43.1, 42.7, 41.6, 43.8 and $40.7 \mathrm{mg} \mathrm{S} \mathrm{g}^{-1}$, respectively).

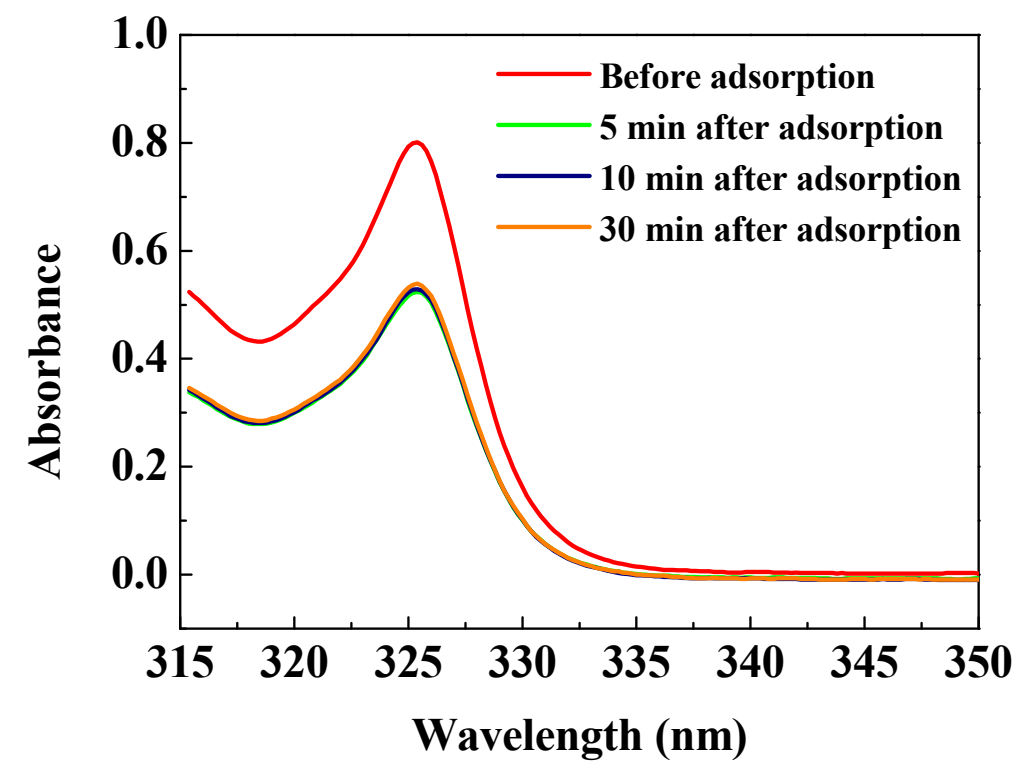

Figure S13. Adsorption curves (The initial concentration of DBT in model oil is $\mathrm{C}_{0}=$ $800 \mathrm{mg} \mathrm{S} \mathrm{L}^{-1}$; the volume of model oil is $3.5 \mathrm{~mL}$; and the mass of adsorbent is 20 mg.). 


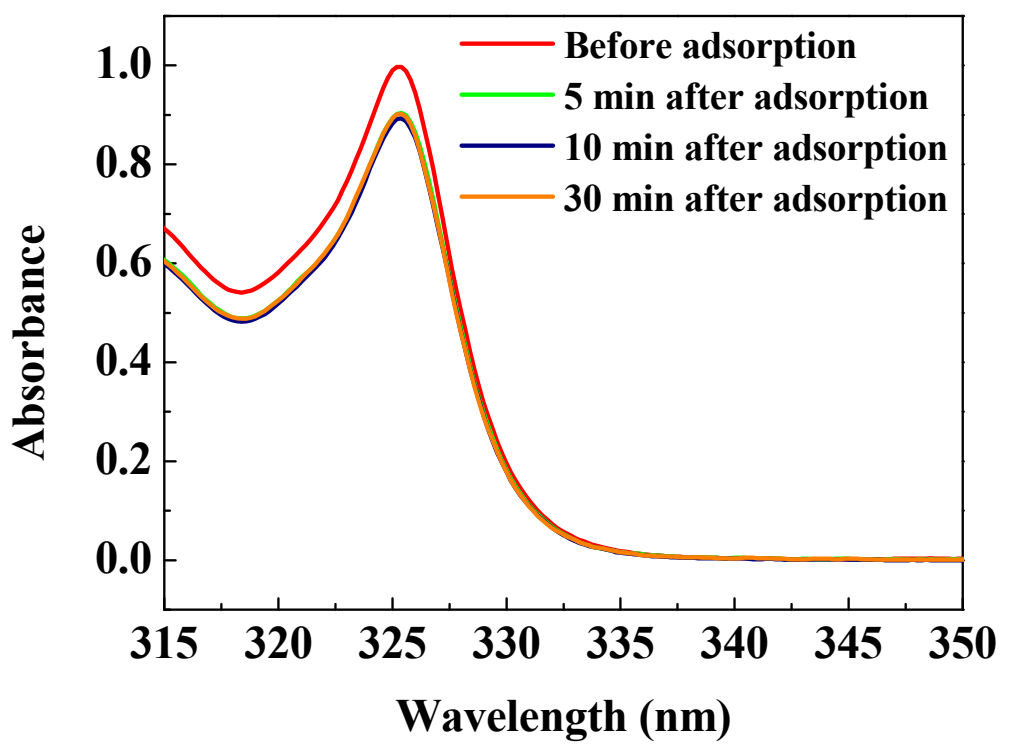

Figure S14. Adsorption curves (The initial concentration of DBT in model oil is $\mathrm{C}_{0}=$ $500 \mathrm{mg} \mathrm{S} \mathrm{L}^{-1}$; the volume of model oil is $10 \mathrm{~mL}$; and the mass of adsorbent is 10 mg.).

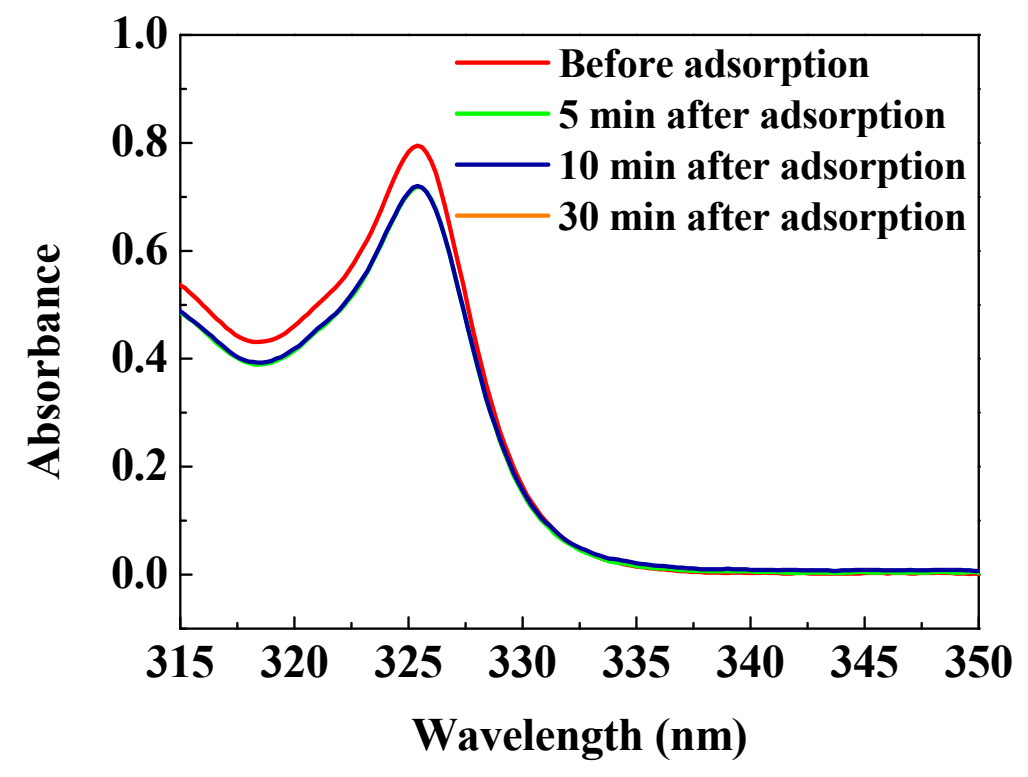

Figure S15. Adsorption curves (The initial concentration of DBT in model oil is $\mathrm{C}_{0}=$ $50 \mathrm{mg} \mathrm{S} \mathrm{L}^{-1}$; the volume of model oil is $20 \mathrm{~mL}$; and the mass of adsorbent is $5 \mathrm{mg}$.). 


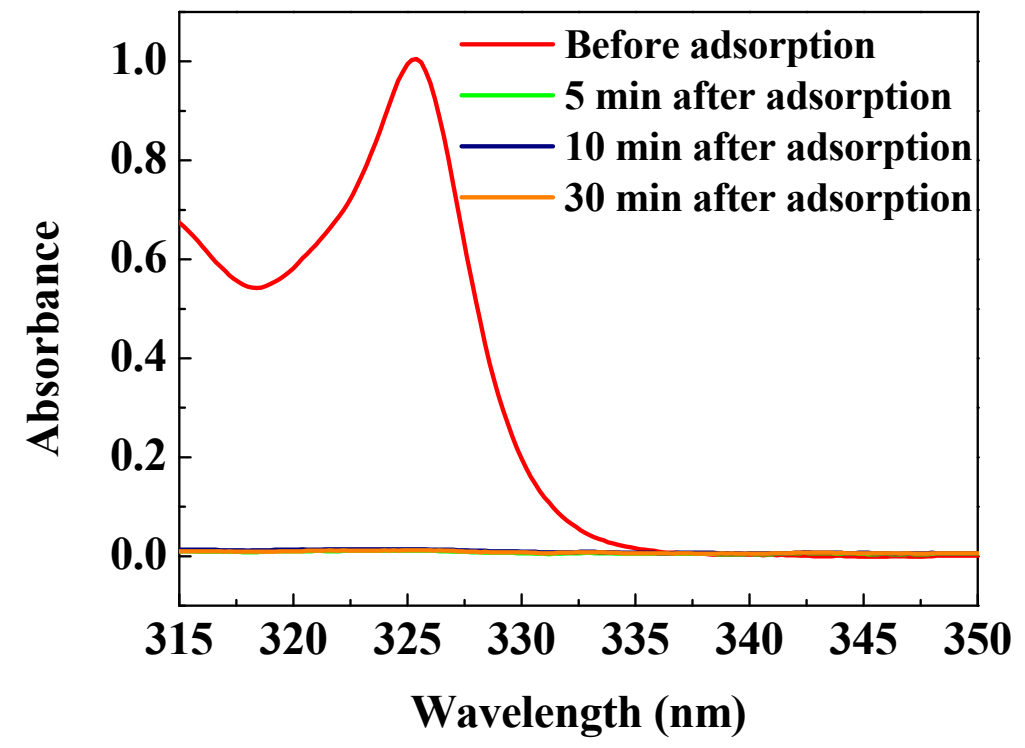

Figure S16. Adsorption curves (The initial concentration of DBT in model oil is $\mathrm{C}_{0}=$ $10 \mathrm{mg} \mathrm{S} \mathrm{L}^{-1}$; the volume of model oil is $3.5 \mathrm{~mL}$; and the mass of adsorbent is $20 \mathrm{mg}$.). 
Table S1. The experimental conditions, parameters and yields of resultant carbonaceous materials

\begin{tabular}{ccccc}
\hline Sample & $\mathrm{m}$ & $\mathrm{m}_{\mathrm{KOH}}: \mathrm{m}_{\text {precursor }}$ & $\mathrm{m}_{\text {product }}$ & yield \\
\hline HAS-1 & 0.5005 & 1 & 0.3079 & $61.52 \%$ \\
HAS-2 & 0.5001 & 1 & 0.2082 & $41.63 \%$ \\
HCT-1 & 0.5002 & 1 & 0.2623 & $52.44 \%$ \\
HCT-2 & 0.5003 & 1 & 0.1774 & $35.46 \%$ \\
HCT-3 & 0.5005 & 1 & 0.1680 & $33.57 \%$ \\
AS-1 & 0.5003 & 1 & 0.3194 & $63.84 \%$ \\
AS-2 & 0.5002 & 1 & 0.1454 & $29.07 \%$ \\
\hline
\end{tabular}

Table S2. Chemical compositions of CHCPs samples by XPS analysis

\begin{tabular}{cccccc}
\hline $\begin{array}{c}\text { Element } \\
(\text { atom \%) }\end{array}$ & CHAS-1 & CHAS-2 & CHCT-1 & CHCT-2 & CHCT-3 \\
\hline C & 90.05 & 88.78 & 91.52 & 88.92 & 90.67 \\
O & 9.95 & 11.22 & 8.48 & 11.08 & 9.33 \\
\hline
\end{tabular}

Table S3. Adsorption capacities of applied CHCPs

\begin{tabular}{cccccc}
\hline Sample & CHAS-1 & CHAS-2 & CHCT-1 & CHCT-2 & CHCT-3 \\
\hline Adsorption & & & & & \\
capacity & 44.0 & 42.9 & 41.1 & 42.5 & 43.1 \\
$\left(\mathrm{mg} \mathrm{S} \mathrm{g} \mathrm{g}^{-1}\right)$ & & & & & \\
\hline
\end{tabular}


Table S4. DBT adsorption isotherm parameters for Langmuir and Freundlich equations

\begin{tabular}{ccccccc}
\hline & \multicolumn{3}{c}{ Langmuir } & \multicolumn{3}{c}{ Freundlich } \\
\cline { 2 - 7 } Adsorbate & $\mathrm{q}_{\mathrm{m}}$ & $\mathrm{K}_{\mathrm{L}}$ & $\mathrm{R}_{\mathrm{L}}{ }^{2}$ & $\mathrm{~K}_{\mathrm{F}}$ & $\mathrm{n}$ & $\mathrm{R}_{\mathrm{F}}{ }^{2}$ \\
& $\left(\mathrm{mg} \mathrm{S} \mathrm{g}^{-1}\right)$ & & & & & \\
\hline DBT & 44.7 & 0.0591 & 0.9969 & 9.549 & 3.759 & 0.9993 \\
\hline
\end{tabular}

Table S5. Adsorption capacities of reported metal-free activated carbons and CHAS-1

\begin{tabular}{|c|c|c|c|}
\hline Sample & $\begin{array}{l}\text { Surface area } \\
\qquad\left(\mathrm{m} 2 \mathrm{~g}^{-1}\right)\end{array}$ & $\begin{array}{c}\text { Adsorption } \\
\text { capacity }\left(\mathrm{mg} \mathrm{S} \mathrm{g}^{-1}\right)\end{array}$ & Reference \\
\hline $\mathrm{BX}$ & 2271 & 33.92 & 20 \\
\hline BPS & 1345 & 47.04 & 20 \\
\hline C-700 & 932 & 49.28 & 21 \\
\hline PCB & 1054 & 16.32 & 48 \\
\hline AC-90 & 796 & 9.28 & 49 \\
\hline $\mathrm{AC}_{\mathrm{S} 250}$ & 1271 & 33.28 & 50 \\
\hline $\mathrm{AC}_{120}$ & 1045 & 30.08 & 51 \\
\hline $\mathrm{AC}_{673}$ & 1077 & 41.60 & 52 \\
\hline AC-WPH & 1087 & 2.88 & 53 \\
\hline ACMB-1 & 2202 & 7.04 & 54 \\
\hline CAU & 1281 & 7.36 & 55 \\
\hline CHAS-1 & 1568 & 44.7 & This work \\
\hline
\end{tabular}

